ACCEPTED MANUSCRIPT

\title{
A method for evaluating the effects of specimen geometry and loading condition on fatigue life of metallic materials
}

To cite this article before publication: Chengqi Sun et al 2019 Mater. Res. Express in press https://doi.org/10.1088/2053-1591/aafbb8

\section{Manuscript version: Accepted Manuscript}

Accepted Manuscript is "the version of the article accepted for publication including all changes made as a result of the peer review process, and which may also include the addition to the article by IOP Publishing of a header, an article ID, a cover sheet and/or an 'Accepted

Manuscript' watermark, but excluding any other editing, typesetting or other changes made by IOP Publishing and/or its licensors"

This Accepted Manuscript is @ 2019 IOP Publishing Ltd.

During the embargo period (the 12 month period from the publication of the Version of Record of this article), the Accepted Manuscript is fully protected by copyright and cannot be reused or reposted elsewhere.

As the Version of Record of this article is going to be / has been published on a subscription basis, this Accepted Manuscript is available for reuse under a CC BY-NC-ND 3.0 licence after the 12 month embargo period.

After the embargo period, everyone is permitted to use copy and redistribute this article for non-commercial purposes only, provided that they adhere to all the terms of the licence https://creativecommons.org/licences/by-nc-nd/3.0

Although reasonable endeavours have been taken to obtain all necessary permissions from third parties to include their copyrighted content within this article, their full citation and copyright line may not be present in this Accepted Manuscript version. Before using any content from this article, please refer to the Version of Record on IOPscience once published for full citation and copyright details, as permissions will likely be required. All third party content is fully copyright protected, unless specifically stated otherwise in the figure caption in the Version of Record.

View the article online for updates and enhancements. 


\title{
A method for evaluating the effects of specimen geometry and
}

\section{loading condition on fatigue life of metallic materials}

\author{
Chengqi Sun ${ }^{\mathrm{a}, \mathrm{b} *}$, Qingyuan Song, \\ ${ }^{a}$ State Key Laboratory of Nonlinear Mechanics, Institute of Mechanics, Chinese Academy of
}

Sciences, Beijing 100190, China

${ }^{b}$ School of Engineering Sciences, University of Chinese Academy of Sciences, Beijing 100049, China

\begin{abstract}
In this paper, the effects of specimen geometry and loading condition on fatigue life are investigated based on statistical analysis and control volume concept. A probabilistic control volume method is developed for correlating the fatigue life of specimens with different control volumes. The predicted P-S-N curves accord with the experimental data for the titanium alloy Ti-6Al-2Sn-2Zr-3Mo-X and the high strength steel JIS SUJ2 in literature. The relative error of the predicted fatigue life at $50 \%$ survival probability to that directly analyzed from the conventional testing method is $-18.7 \%$ for the specimens of titanium alloy. The paper also indicates that the determination of the control volume should be based on the fatigue failure mechanism of specimens, which is appropriate to use the control volume for the interior induced fatigue failure and the control surface with a certain thickness for the surface induced fatigue failure.
\end{abstract}

Keywords: specimen geometry; loading condition; control volume; fatigue life; metallic materials

* Corresponding author

Email address: scq@lnm.imech.ac.cn 


\section{Introduction}

Fatigue failure is very common phenomenon in materials and structure parts [1-3]. One of the most important factors influencing the fatigue behavior is the effects of specimen geometry and loading condition [4-7]. For example, large specimens usually present short fatigue life compared to the smaller specimens due to the high/possibility of material defects or microstructure inhomogeneities. On the other hand, the specimen (e.g. a notched specimen) with a large stress gradient at its most highly stressed location generally endures the higher local stress amplitude than that of the smooth specimen for the same fatigue cycles $[8,9]$. Therefore, it is vital to model the effects of specimen geometry and loading condition on the fatigue life or fatigue strength of metallic materials.

The effects of specimen size, notch geometry and loading condition on fatigue life or fatigue strength have drawn great attention [10-13]. For example, Murakami et al. [14] used the control volume method to investigate the difference of fatigue strength by axial fatigue test and rotating bending fatigue test for high strength steels. The control volume is a highly stressed domain of a specimen or a component, where the fatigue crack might initiate [15]. Sun et al. [16] correlated the fatigue life of small specimens and that of large specimens by the assumption that large specimens could be seen composed of a number of small specimens via the control volume. It was shown that, if the fatigue life of small specimens followed Weibull distribution with the scale parameter $\lambda$ and the shape parameter $k$, the fatigue life of large specimens followed the Weibull distribution with the scale parameter $n^{-1 / k} \lambda$, where $n$ is an approximate integer presenting the ratio of the control volume of the large specimen to that of the small specimen. Then, the fatigue life of the large specimen could be analyzed by using the fatigue life data of small specimens. Lanning et al. [17] used the weakest-link method for predicting the high 
cycle fatigue strength of notched components. Berto \& Lazzarin $[18,19]$ applied the strain energy density approach averaged over a control volume to investigate the fatigue strength of notched components. Wang et al. [20] combined the critical distance and the highly stressed volume method to evaluate the size effect of the stress concentrator on low cycle fatigue of TA19 plate, and showed that the combining method gave a better prediction of the size effect than the critical distance method alone. Härkegård \& Halleraker [21] ranked the Neuber's and Peterson's method, peak stress method, critical distance method, stress gradient method, highly stressed volume method and weakest-link method, according to their predictive capability for the notch and size effect at the fatigue limit based on the data by Böhm and Magin. It was shown that the stress gradient, weakest-link and highly stressed volume methods gave the best predictions.

In this work, the effects of specimen geometry and loading condition on fatigue life are studied, and a probabilistic control volume method is proposed for correlating the effects of specimen geometry and loading condition on fatigue life based on statistical analysis and control volume concept. The predicted P-S-N curves are compared with the experimental data in literature and the data directly analyzed from the conventional testing method. The determination of the control volume is also discussed.

\section{A probabilistic control volume method}

According to the wok by Sun et al. [16], if a normal specimen A with control volume $V_{A}$ could be seen composed of a number of specimen $C$ with very small control volume $V_{C}$ from the same material and the same production procedure through control volume, the fatigue life of specimen A could be analyzed by using the fatigue life data of specimen C. Here, the fatigue life in logarithmic scale $N_{C}$ of specimen C under a 
certain stress level is assumed to follow 3-parameter Weibull distribution, i.e.

$$
F_{N_{C}}(x)= \begin{cases}1-e^{-\left(\frac{x-\gamma}{\lambda}\right)^{k}} & x \geq \gamma, \\ 0 & x<\gamma\end{cases}
$$

where $\lambda>0$ is the scale parameter, $k>0$ is the shape parameter and $\gamma \geq 0$ is the location parameter.

At the same stress level, the cumulative distribution function for the fatigue life in logarithmic scale $N_{A}$ of specimen A satisfies

$$
\begin{aligned}
F_{N_{A}}(x)= & P\left\{N_{A} \leq x\right\} \\
= & P\left\{\min \left\{N_{C, 1}, N_{C, 2}, \cdots, N_{C, n_{A}}\right\} \leq x\right\} \\
= & 1-P\left\{N_{C, 1}>x\right\} P\left\{N_{C, 2}>x\right\} \cdots P\left\{N_{C, n_{A}}>x\right\} \\
= & 1-\left[1-F_{N_{C}}(x)\right]^{n_{A}} \\
& = \begin{cases}1-e^{-\left(\frac{x-\gamma}{\lambda n_{A}^{-1 / k}}\right)^{k}} \quad x \geq \gamma \\
0 & x<\gamma\end{cases}
\end{aligned}
$$

where $n_{A}$ is an approximate integer part of $V_{A} / V_{C}$.

From Eqs. (1) and (2), we have $1-F_{N_{A}}(x)=1-F_{N_{C}}(x)$ at the same survival probability, i.e.

$$
e^{-\left(\frac{N_{A}-\gamma}{\lambda n_{A}^{-1 / k}}\right)^{k}}=e^{-\left(\frac{N_{C}-\gamma}{\lambda}\right)^{k}}
$$

Eq. (3) could be written as

$$
\frac{N_{A}-\gamma}{N_{C}-\gamma}=n_{A}^{-\frac{1}{k}}
$$

In the same way, for specimen B with control volume $V_{B}$, we have

$$
\frac{N_{B}-\gamma}{N_{C}-\gamma}=n_{B}^{-\frac{1}{k}}
$$

where $N_{B}$ is the fatigue life in logarithmic scale of specimen $B$ and $n_{B}$ is an integer part 
of $V_{B} / V_{C}$.

Considering that the specimen $\mathrm{C}$ with very small control volume (e.g. $0.01 \mathrm{~mm}^{3}$ ), we have

$$
n_{A}=\frac{V_{A}}{V_{C}} \text { and } n_{B}=\frac{V_{B}}{V_{C}}
$$

By using Eqs. (4)-(6), we have

$$
\frac{N_{A}-\gamma}{N_{B}-\gamma}=\left(\frac{V_{A}}{V_{B}}\right)^{-\frac{1}{k}}
$$

Especially, for the crack initiates from the surface, the highly stressed region of the surface (i.e. control surface) with a certain thickness $h$ (e.g. the magnitude of several grains) should be used [16]. In this case, Eq. (7) is written as

$$
\frac{N_{A}-\gamma}{N_{B}-\gamma}=\left(\frac{S_{A}}{S_{B}}\right)^{-\frac{1}{k}}
$$

where $S_{A}$ denotes the control surface of specimen $A$ and $S_{B}$ denotes the control surface of specimen B.

As a special case, if the fatigue life in logarithmic scale following the two-parameter Weibull distribution, we have

$$
\begin{aligned}
& \frac{N_{A}}{N_{B}}=\left(\frac{V_{A}}{V_{B}}\right)^{-\frac{1}{k}} \\
& \frac{N_{A}}{N_{B}}=\left(\frac{S_{A}}{S_{B}}\right)^{-\frac{1}{k}}
\end{aligned}
$$

Eqs. (7)-(10) give the relation for the fatigue life of specimens with different control volumes, which indicate that the effects of specimen geometry and loading condition on fatigue life is related to the control volume of specimens and the parameters of the Weibull distribution of fatigue life in logarithmic scale. Moreover, Eqs. (7) and (8) 
indicate that the fatigue life in logarithmic scale tends to the minimum value $\gamma$, which accords with the fact that the fatigue life cannot decrease infinitely with increasing the specimen size.

\section{Comparison with experimental results}

Here, the two-parameter Weibull distribution is assumed for the fatigue life in logarithm of base 10. Regarding to the fatigue life under different stress levels, the method by Sun et al. [16] is used to transform the fatigue life under different stress levels to that under an arbitrary given stress level, and then the parameters of Weibull distribution and the fatigue life at some certain survival probabilities are obtained.

\subsection{Comparison with experimental data of a titanium alloy}

Figure 1 shows the comparison of the predicted P-S-N curves by the method in Ref. [16] with the experimental data for the hourglass specimen under conventional frequency axial fatigue test [22]. The original experimental data are given in Table 1. It is seen that the experimental data in general scatter on both sides of the predicted $50 \%$ survival probability curve and are within the predicted 5\% and 95\% survival probability curves, indicating that the predicted P-S-N curves accord with the experimental data. For a further comparison with the experimental data, Fig. 1 also shows the fatigue life at 5\%, 50\% and 95\% survival probabilities directly obtained from the statistical analysis (i.e. the conventional testing method) for all the 8 fatigue life data at $\sigma_{a}=693 \mathrm{MPa}$. It is seen that, the predicted fatigue life at $5 \%, 50 \%$ and $95 \%$ survival probabilities is in agreement with the ones by the conventional testing method. The relative errors of the former to the latter are $35.9 \%, 12.7 \%$ and $-11.3 \%$, respectively. This further indicates that the method in Ref. [16] could be used for the P-S-N curve prediction. 
Figure 2 shows the comparison of the predicted P-S-N curves with the experimental data for the hourglass specimen and the notch specimen under rotating bending fatigue test [13] by the present method using the experimental data of the hourglass specimen under conventional frequency axial fatigue test [22]. For the hourglass specimen under rotating bending fatigue test, the fatigue life at 5\%, 50\% and 95\% survival probabilities obtained directly from the statistical analysis for all the 17 fatigue life data at $\sigma_{a}=706.2$ MPa are also compared. The original experimental data of the specimens under rotating bending fatigue test are given in Table 1. Considering that all the hourglass and notch specimens under rotating bending fatigue test fail from the specimen surface and that only one hourglass specimen under axial loading fatigue test fails from the interior of specimen, the present method with control surface (i.e. Eq. 10) might be appropriate for correlating the effects of specimen geometry and loading condition on the fatigue life. The predicted results by the present method using the control volume (i.e. Eq. 9) are also compared. Here, the control surface and the control volume are taken as the region no less than $90 \%$ of the maximum principal stress $[10,15,16,21]$ and obtained by finite element calculation, as shown in Table 2.

It is seen that the predicted P-S-N curves by using control surface accord with the experimental data, which is much better than the predicted ones by using the control volume. The fatigue life at $5 \%, 50 \%$ and $95 \%$ survival probabilities predicted by the present method using control surface is also very close to the fatigue life directly analyzed from the conventional testing method. The relative errors of the former to the latter are $-56.1 \%,-18.7 \%$ and $76.3 \%$, respectively. While the relative errors are very large for the fatigue life predicted by using control volume, which are $761.4 \%, 941.5 \%$ and 1323.3\%, respectively, as shown in Table 3. This indicates that the determination of the control region is crucial for the application of control volume method. For the crack 
initiates from the surface of specimen, the fatigue life is dominated by the highly stressed region of the surface with a certain thickness. In this case, it is appropriate to take the control surface with a certain thickness for correlating the effects of specimen geometry and loading condition on fatigue life by using the control volume method.

\subsection{Comparison with experimental data of a high strength steel}

Here, the proposed method is used for evaluating the effect of loading condition (rotating bending and axial loading) on the fatigue life of a high strength steel JIS SUJ2 in literature [23,24]. The experimental results indicate that this high strength steel presents different failure modes from low cycle fatigue to very high cycle fatigue (VHCF) regime. In low cycle fatigue regime, the fatigue fáilure initiates from the surface slip. In VHCF regime, the fatigue failure initiates from inclusions. In high cycle fatigue regime, the two failure modes could coexist at the same stress amplitude, and the fatigue life generally has a larger difference at different failure modes. In this case, the specimens with the same failure mode that the fatigue failure initiates from inclusions are considered, and the present method with control volume (i.e. Eq. 9) is more appropriate due to the fact that most specimens initiate from the interior of specimens. The predicted results by using the control surface (i.e. Eq. 10) are also compared. The control volume and control surface are $1.10 \mathrm{~mm}^{3}$ and $14.99 \mathrm{~mm}^{2}$ for the specimens under rotating bending fatigue test, respectively, and $17.49 \mathrm{~mm}^{3}$ and 29.92 $\mathrm{mm}^{2}$ for the specimens under axial loading fatigue test, respectively.

Figure 3 shows the comparison of the predicted P-S-N curves by the method in Ref. [16] with the experimental data of the specimen under rotating bending fatigue test $[23,24]$. It is seen that the predicted P-S-N curves are in agreement with the experimental data. 
Figure 4 shows the comparison of predicted P-S-N curves with experimental data under axial loading fatigue test by the ones under rotating bending fatigue test $[23,24]$. It is seen that the predicted P-S-N curves by using the control volume are in agreement with the experimental data under axial loading fatigue test, which seems to be better than the predicted results through the control surface.

According to the work by Nakajima et al. [23,24], the inclusions as crack origin are located within $0.175 \mathrm{~mm}$ depth from the specimen surface due to the presence of stress gradient under rotating bending fatigue test, which is very close to the depth of 0.160 mm calculated from finite element analysis by the control volume. This indicates that the control volume is consistent with the region where the fatigue crack might initiate, i.e. it is reasonable to use the control volume for correlating the effect of loading condition on the fatigue life for the crack initiation from inclusions.

Comparison of the predicted P-S-N curves with the experimental data for the titanium alloy Ti-6Al-2Sn-2Zr-3Mo-X and the high strength steel JIS SUJ2 in literature indicates that the proposed method is able to reflect the effects of specimen geometry and loading condition on fatigue life.

It is noted that, the premise of the present method is that the normal specimens could be seen as a number of small specimens through the control volume and that the fatigue life for the normal specimens could be taken as the minimum fatigue life among these small specimens [16]. So, the present method might be invalid for the effects of specimen geometry and loading condition on the fatigue life of specimens with different failure mechanism [25] or for the fatigue failure with multiple crack initiation and crack propagation with mutual interactions [26].

\section{Conclusions}


In this paper, a probabilistic control volume method is proposed for evaluating the effects of specimen geometry and loading condition on fatigue life based on statistical analysis and control volume concept. The predicted results are in agreement with the experimental data of the titanium alloy Ti-6Al-2Sn-2Zr-3Mo-X and the high strength steel JIS SUJ2 in literature. It also suggests that the determination of the control volume should be based on the fatigue failure mechanism of specimens. For the surface induced fatigue failure, it is appropriate to use the control surface with a certain thickness for correlating the effects of specimen geometry and loading condition on fatigue life. The proposed method might be promising in evaluating the effects of specimen geometry and loading condition on fatigue life of metallic materials.

\section{Acknowledgments}

The authors would like to acknowledge the support from the National Key Research and Development Program of China “Genera Design, Construction and Sea Trial of Full Ocean Deep Manned Submersible” (2016YFC0300600), the Innovation Program (237099000000170004) and the Strategic Priority Research Program of the Chinese Academy of Sciences (XDB22040503, XDB22020201, XDB22020200).

\section{References}

[1] Wu, S.C.; Liu, Y.X.; Li, C.H.; Kang, G.Z.; Liang, S.L. On the fatigue performance and residual life of intercity railway axles with inside axle boxes. Eng. Fract. Mech. 2018, 197: $176-191$

[2] Beretta, S.; Ghidini, A.; Lombardo, F. Fracture mechanics and scale effects in the fatigue of railway axles. Eng. Fract. Mech. 2005, 72: 195-208.

[3] Huang, Z.; Wagner, D.; Bathias, C.; Paris, P.C. Subsurface crack initiation and propagation mechanisms in gigacycle fatigue. Acta Mater. 2010, 58: 6046-6054. 
[4] Akiniwa, Y.; Miyamoto, N.; Tsuru, H.; Tanaka, K. Notch effect on fatigue strength reduction of bearing steel in the very high cycle regime. Int. J. Fatigue 2006, 28: 15551565.

[5] Shirani, M.; Härkegård, G. Fatigue life distribution and size effect in ductile cast iron for wind turbine components. Eng. Fail. Anal. 2011, 18: 12-24.

[6] Furuya, Y. Specimen size effects on gigacycle fatigue properties of high-strength steel under ultrasonic fatigue testing. Scr. Mater. 2008, 58: 1014-1017.

[7] Shiozawa, K.; Hasegawa, T.; Kashiwagi, Y.; Lu, L. Very high cycle fatigue properties of bearing steel under axial loading condition. Int. J. Fatigue 2009, 31: 880-888.

[8] Chen, S.; Li, Y.; Liu, Y.; Yang, Z.; Li, S.; Zhang, Z. Fatigue strengths of the 54SiCr6 steel under different cyclic loading conditions. Acta Metall. Sin. 2009, 45: 428-433.

[9] Qian, G.; Hong, Y.; Zhou, C. Investigation of high cycle and Very-High-Cycle Fatigue behaviors for a structural steel with smooth and notched specimens. Eng. Fail. Anal. 2010, 17: 1517-1525.

[10] Kuguel, R.A. A relation between theoretical stress concentration factor and fatigue notch factor deduced from the concept of highly stressed volume. ASTM Proc. 1961, 61, 732748.

[11] Lin, C.K.; Lee, W.J. Effects of highly, stressed volume on fatigue strength of austempered ductile irons. Int. J. Fatigue 1998, 20, 301-307.

[12] Lei, Z.; Xie, J.; Sun, C.; Hong, Y. Effect of loading condition on very-high-cycle fatigue behavior and dominant variable analysis. Sci. China-Phys. Mech. Astron. 2014, 57: 74-82.

[13] Sun, C.; Song, Q. A method for predicting the effects of specimen geometry and loading condition on fatigue strength. Metals 2018, 8: 811.

[14] Murakami, Y.; Yokoyama, N.N.; Nagata, J. Mechanism of fatigue failure in ultralong life regime. Fatigue Fract. Eng. Mater. Struct. 2002, 25: 735-746.

[15] Murakami, Y. Metal Fatigue: Effects of Small Defects and Nonmetallic Inclusions; Elsevier Science Ltd.: Oxford, UK, 2002; pp. 333-336.

[16] Sun, C.; Zhang, X.; Liu, X.; Hong, Y. Effects of specimen size on fatigue life of metallic 
materials in high-cycle and very-high-cycle fatigue regimes. Fatigue Fract. Eng. Mater. Struct. 2016, 39, 770-779.

[17] Lanning, D.B.; Nicholas, T.; Palazotto, A. HCF notch predictions based on weakest-link failure models. Int. J. Fatigue 2003, 25, 835-841.

[18] Berto, F.; Lazzarin, P. A review of the volume-based strain energy density approach applied to V-notches and welded structures. Theor. Appl. Fract. Mech. 2009, 52: 183-194.

[19] Berto, F.; Lazzarin, P. Fatigue strength of Al7075 notched plates based on the locál SED averaged over a control volume. Sci. China Phys. Mech. Astron. 2014, 57: 30-38.

[20] Wang, G.Y.; Liaw, P.K.; Yokoyama, Y.; Inoue A. Size effects on the fatigue behavior of bulk metallic glasses. J. Appl. Phys. 2011, 110: 113507.

[21] Härkegård, G.; Halleraker, G. Assessment of methods for prediction of notch and size effects at the fatigue limit based on test data by Böhm and Magin. Int. J. Fatigue 2010, 32: 1701-1709.

[22] Li, Y.; Song, Q.; Feng, S.; Sun, C. Effects of loading frequency and specimen geometry on high cycle and very high cycle fatigue life of a high strength titanium alloy. Materials 2018, 11: 1628.

[23] Nakajima, M.; Sakai, T.; Shimizu, T. An observation of fish-eye fracture process in high strength steel SUJ2. Trans. Jpn. Soc. Mech. Eng. A 1999, 65: 2504-2510.

[24] Nakajima, M.; Tokaji, K.; Itoga, H.; Shimizu, T. Effect of loading condition on very high cycle fatigue behavior in a high strength steel. Int. J. Fatigue 2010, 32: 475-480.

[25] Wang, G.Y.; Liaw, P.K.; Yokoyama, Y.; Inoue A. Size effects on the fatigue behavior of bulk metallic glasses. J. Appl. Phys. 2011, 110: 113507.

[26] Zhu, S.P.; Foletti, S.; Beretta, S. Evaluation of size effect on strain-controlled fatigue behavior of a quench and tempered rotor steel: Experimental and numerical study. Mater. Sci. Eng. A, 2018, 735, 423-435. 


\section{Figures and figure captions}

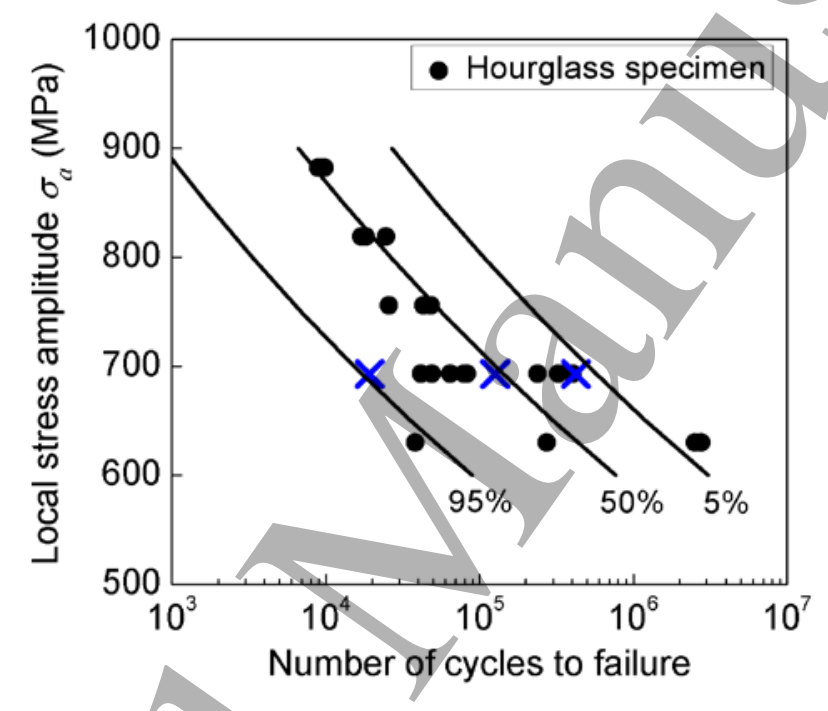

Figure 1. Comparison of predicted P-S-N curves by the method in Ref. [16] with the experimental results for the hourglass specimen under conventional frequency axial fatigue test [22], in which the symbol cross denotes the fatigue life at 5\%, 50\% and 95\% survival probabilities obtained directly from the statistical analysis of the 8 fatigue life data at $\sigma_{a}=$ $693 \mathrm{MPa}$. 

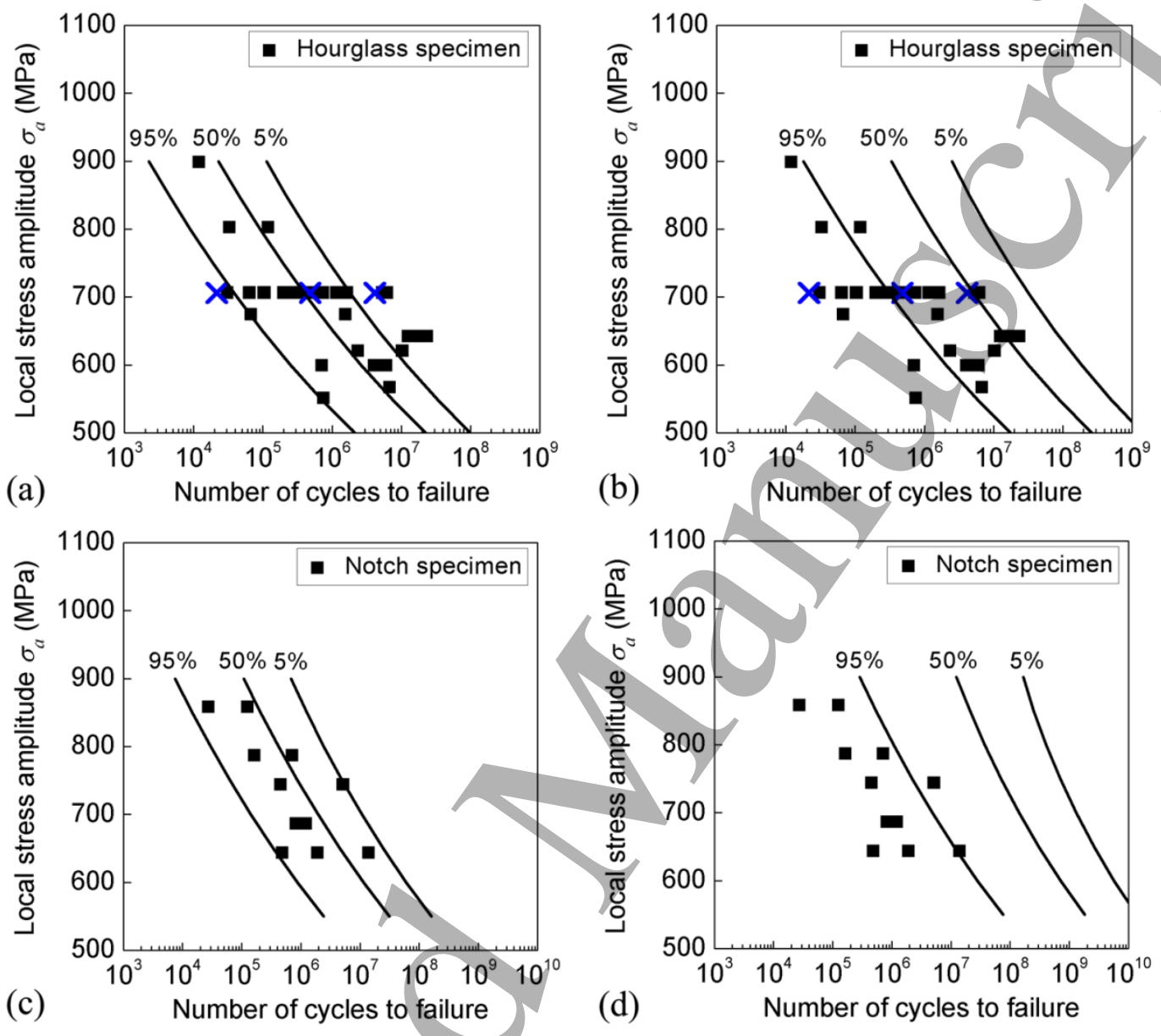

Figure 2. Comparison of predicted P-S-N curves with the experimental data for the hourglass specimen and notch specimen under rotating bending fatigue test [13] by the experimental data of the hourglass specimen under conventional frequency axial fatigue test [22], in which the symbol cross denotes the fatigue life at 5\%, 50\% and $95 \%$ survival probabilities obtained directly from the statistical analysis of the 17 fatigue life data at $\sigma_{a}=$ 706.2 MPa for the hourglass specimen under rotating bending fatigue test. (a), (c) The present method using control surface; (b), (d) The present method using control volume. 


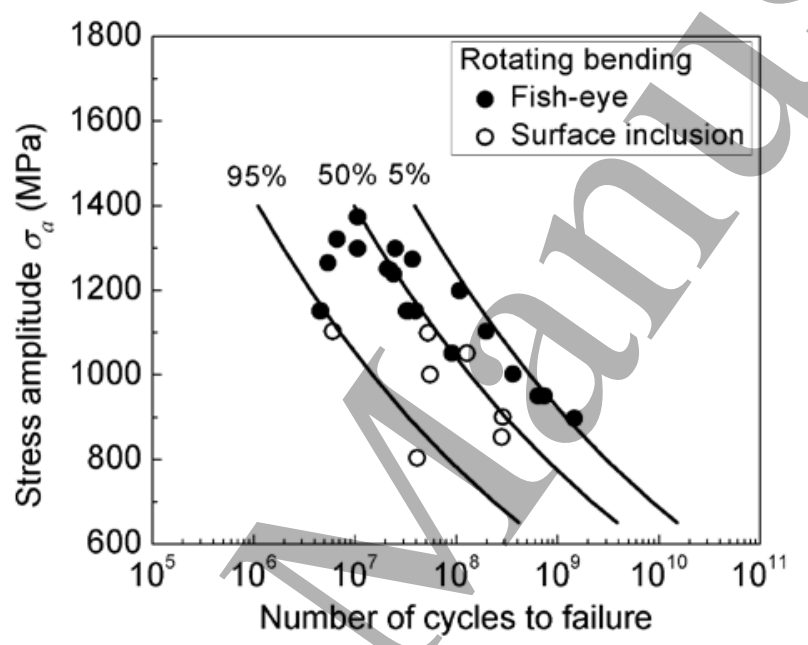

Figure 3. Comparison of predicted P-S-N curves by the method in Ref. [16] with the experimental data of the specimen under rotating bending fatigue test [23,24]. 

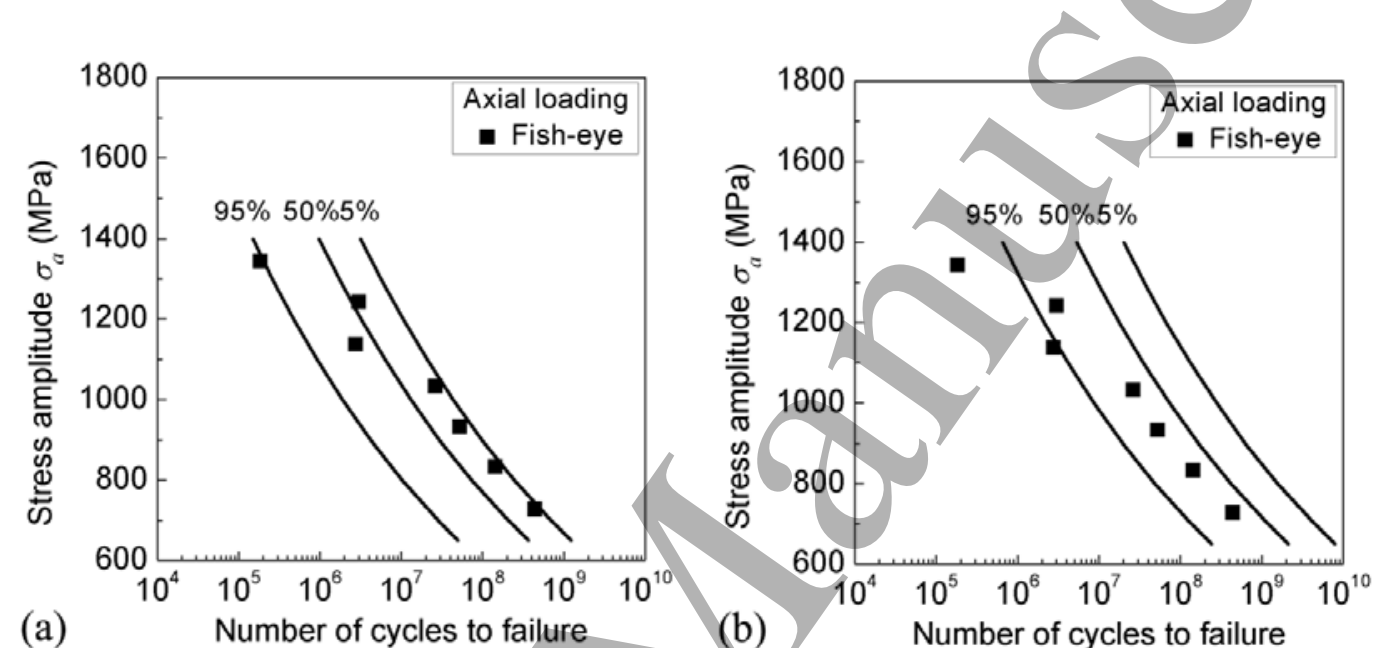

Figure 4. Comparison of predicted P-S-N curves with experimental data under axial loading fatigue test by the ones under rotating bending fatigue test in literature [23,24]. (a) The present method using control volume; (b) The present method using control surface. 
Tables and table captions

Table 1. Original experimental data of specimens shown in Figs. 1 and 2.

\begin{tabular}{|c|c|c|c|c|}
\hline \multicolumn{2}{|c|}{$\begin{array}{c}\text { Hourglass specimen } \\
\text { under conventional frequency } \\
\text { axial fatigue test }\end{array}$} & \multicolumn{2}{|c|}{$\begin{array}{c}\text { Hourglass specimen } \\
\text { under rotating bending } \\
\text { fatigue test } \\
\end{array}$} & $\begin{array}{c}\text { Notch specimen } \\
\text { under rotating bending } \\
\text { fatigue test }\end{array}$ \\
\hline$\sigma_{a}(\mathrm{MPa})$ & $N_{f}$ (cycle) & $\sigma_{a}(\mathrm{MPa})$ & $N_{f}$ (cycle) & $\sigma_{a}(\mathrm{MPa}) \quad N_{f}($ cycle $)$ \\
\hline 882 & $8.98 \times 10^{3}$ & 898.8 & $1.20 \times 10^{4}$ & $1.25 \times 10^{5}$ \\
\hline 882 & $9.40 \times 10^{3}$ & 802.5 & $1.20 \times 10^{5}$ & $2.74 \times 10^{4}$ \\
\hline 882 & $9.82 \times 10^{3}$ & 802.5 & $3.30 \times 10^{4}$ & $1.64 \times 10^{5}$ \\
\hline 819 & $1.79 \times 10^{4}$ & 706.2 & $4.96 \times 10^{5}$ & $7.20 \times 10^{5}$ \\
\hline 819 & $2.48 \times 10^{4}$ & 706.2 & $4.05 \times 10^{5}$ & $4.56 \times 10^{5}$ \\
\hline 819 & $1.82 \times 10^{4}$ & 706.2 & $1.67 \times 10^{6}$ & $5.21 \times 10^{6}$ \\
\hline 819 & $1.70 \times 10^{4}$ & 706.2 & $6.25 \times 10^{6}$ & $8.33 \times 10^{5}$ \\
\hline 756 & $4.34 \times 10^{4}$ & 706.2 & $2.22 \times 10^{5}$ & $1.22 \times 10^{6}$ \\
\hline 756 & $4.36 \times 10^{4}$ & 706.2 & $5.32 \times 10^{6}$ & $1.92 \times 10^{6}$ \\
\hline 756 & $2.58 \times 10^{4}$ & 706.2 & $6.43 \times 10^{4}$ & $1.41 \times 10^{7}$ \\
\hline 756 & $4.83 \times 10^{4}$ & 706.2 & $1.16 \times 10^{6}$ & $4.86 \times 10^{5}$ \\
\hline 693 & $2.39 \times 10^{5}$ & 706.2 & $2.01 \times 10^{5}$ & \\
\hline 693 & $6.45 \times 10^{4}$ & 706.2 & $2.96 \times 10^{5}$ & \\
\hline 693 & $3.27 \times 10^{5}$ & 706.2 & $1.07 \times 10^{5}$ & \\
\hline 693 & $7.97 \times 10^{4}$ & 706.2 & $1.59 \times 10^{6}$ & \\
\hline 693 & $4.04 \times 10^{5}$ & 706.2 & $3.66 \times 10^{5}$ & \\
\hline 693 & $4.16 \times 10^{4}$ & 706.2 & $2.27 \times 10^{5}$ & \\
\hline 693 & $4.90 \times 10^{4}$ & 706.2 & $1.04 \times 10^{5}$ & \\
\hline 693 & $8.29 \times 10^{4}$ & 706.2 & $7.47 \times 10^{5}$ & \\
\hline 630 & $2.74 \times 10^{5}$ & 706.2 & $3.07 \times 10^{4}$ & \\
\hline 630 & & 674.1 & $1.57 \times 10^{6}$ & \\
\hline 630 & & 674.1 & $6.78 \times 10^{4}$ & \\
\hline \multirow[t]{10}{*}{630} & & 642 & $1.82 \times 10^{7}$ & \\
\hline & & 642 & $2.37 \times 10^{7}$ & \\
\hline & & 642 & $1.27 \times 10^{7}$ & \\
\hline & & 620.6 & $2.38 \times 10^{6}$ & \\
\hline & & 620.6 & $1.04 \times 10^{7}$ & \\
\hline & & 599.2 & $4.06 \times 10^{6}$ & \\
\hline & & 599.2 & $7.18 \times 10^{5}$ & \\
\hline & & 599.2 & $6.13 \times 10^{6}$ & \\
\hline & & 567.1 & $6.87 \times 10^{6}$ & \\
\hline & & 551.05 & $7.54 \times 10^{5}$ & \\
\hline
\end{tabular}


Table 2. Control surface and control volume of specimens under different loading conditions.

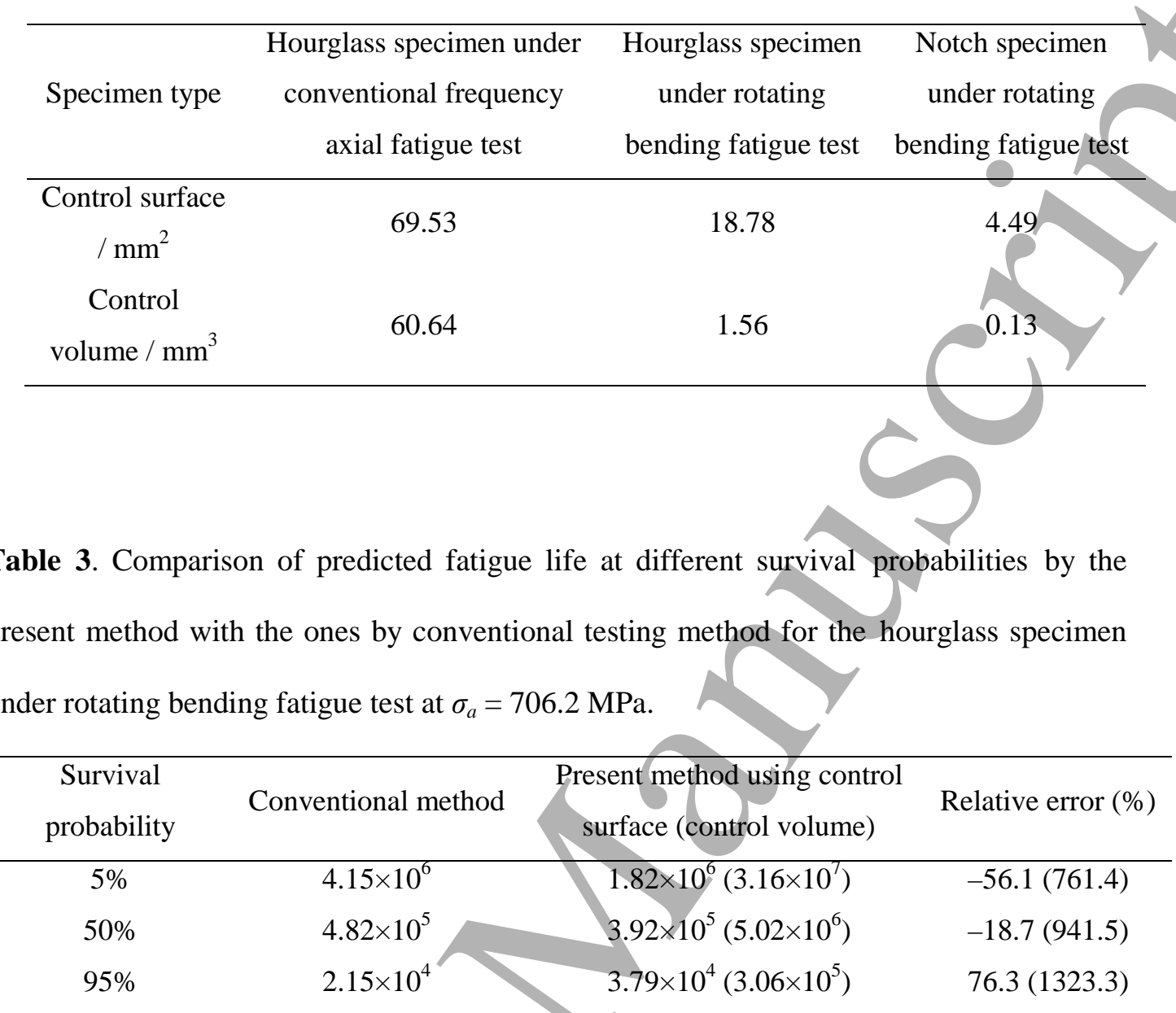

